\title{
Penerapan Metode Dekomposisi Adomian Laplace Dalam Menentukan Solusi Persamaan Panas
}

\author{
Muhammad Abdy ${ }^{1}$, Syafruddin Side ${ }^{1}$, dan Reza Arisandi ${ }^{1, \text { a) }}$ \\ ${ }^{1}$ Jurusan Matematika FMIPA Universitas Negeri Makassar \\ a) ezareza117@gmail.com
}

\begin{abstract}
Abstrak. Artikel ini membahas tentang penerapan Metode Dekomposisi Adomian Laplace (LADM) dalam menentukan solusi persamaan panas. Metode Dekomposisi Adomian Laplace merupakan metode semi analitik untuk menyelesaikan persamaan diferensial nonlinier yang mengkombinasikan antara tranformasi Laplace dan metode dekomposisi Adomian. Berdasarkan hasil perhitungan, metode dekomposisi Adomian Laplace dapat menghampiri penyelesaian persamaan diferensial biasa nonlinear.
\end{abstract}

Kata kunci: Metode Dekomposisi Adomian Laplace, Persamaan Diferensial Parsial, Persamaan Panas

\begin{abstract}
This study discusses the application of Adomian Laplace Decomposition Method (ALDM) in determining the solution of heat equation. Adomian Laplace Decomposition Method is a semi analytical method to solve nonlinear differential equations that combine Laplace transform and Adomian decomposition method. Based on the calculation result, Adomian Laplace decomposition method can approach the settlement of ordinary nonlinear differential equations.
\end{abstract}

Keywords: Adomian Laplace Decomposition Method, Partial Differential Equation, Heat Equation.

\section{PENDAHULUAN}

Matematika merupakan ilmu pengetahuan dasar yang dibutuhkan semua manusia dalam kehidupan sehari-hari baik secara langsung maupun tidak langsung yang dapat digunakan sebagai alat bantu dalam menyelesaikan masalah, seperti cara berhitung ataupun hanya sebagai simbolsimbol yang menyederhanakannya. Seringkali juga ditemukan masalah-masalah dalam menyelesaikan model-model matematika. Beberapa model matematika yang ada, diantaranya adalah tentang persamaan diferensial. Persamaan diferensial merupakan persamaan yang berkaitan dengan turunan suatu fungsi atau memuat suku-suku dari fungsi tersebut dan turunannya. Dengan melibatkan banyak variabel bebas, maka ada dua bentuk persamaan diferensial yaitu persamaan diferensial biasa dan persamaan diferensial parsial (Wahidah,2015) .

Persamaan diferensial biasa adalah persamaan yang hanya memuat turunan yang terdiri dari satu atau lebih variabel tak bebas dengan satu variabel bebas, sedangkan persamaan diferensial parsial adalah persamaan yang memuat turunan parsial satu atau lebih variabel tak bebas terhadap dua atau lebih variabel bebas (Side,2016).

Dalam persamaan diferensial parsial banyak ditemukan masalah pada proses pemodelan matematika, diantaranya pada pemodelan persamaan panas, persamaan gelombang, persamaan Laplace, dan persamaan telegraf. Penyelesaian permasalahan tersebut dapat dilakukan dengan berbagai metode Salah satu permasalahan dalam persamaan panas yaitu masalah distribusi panas 
pada suatu batang penghantar. Dari permasalahan tersebut akan didapatkan suatu persamaan yang disebut persamaan panas. Persamaan panas tersebut inilah yang dapat diselesaikan dengan sebuah metode yang dikenalkan oleh George Adomian seorang matematikawan dari Amerika, dimana metode tersebut lebih dikenal dengan Metode Dekomposisi Adomian. Pada metode ini, persamaan diferensial ditulis dalam bentuk persamaan operator. Operator yang digunakan merupakan operator diferensial. Selanjutnya, operator diferensial pada Metode Dekomposisi Adomian diganti dengan operator transformasi Laplace $\mathcal{L}$ dan invers dari operator $\mathcal{L}$ adalah invers transformasi Laplace $L^{-1}$. Selanjutnya, metode ini disebut Metode Dekomposisi Adomian Laplace (Yuni, 2012 ).

Persamaan konduksi panas sebelumnya telah diterapkan (Ivan, 2011) dalam artikelnya yang berjudul " Metode elemen batas untuk model konduksi panas". Pada penelitian tersebut persamaan panas diselesaikan dengan metode elemen batas agar dapat diperoleh solusi numeriknya. Selain itu, ada juga, penelitian (Yuni, 2012) yang berjudul "Metode Dekomposisi Adomian Laplace untuk Solusi Persamaan Diferensial Nonlinear Koefisien Fungsi", penelitian ini menggabungkan teori transformasi Laplace dan bagian nonlinear dari persamaan diferensial diuraikan dengan polinomial Adomian.

Sesuai dengan uraian di atas, maka penulis bermaksud untuk mempelajari dan mengkaji metode tersebut dalam menentukan solusi persamaan diferensial parsial yaitu pada persamaan panas. Namun, pada artikel ini penulis memberikan batasan masalah yaitu pada persamaan panas dimensi satu.

\section{MATERI DAN METODE}

\section{Metode Dekomposisi Adomian}

Metode Dekomposisi Adomian dikemukakan oleh seorang ahli ilmu matematika dari Amerika yaitu George Adomian (1922-1996). Pada metode ini, persamaan diferensial yang diberikan ditulis dalam bentuk persamaan operator (Wartono, 2013 ).

Diberikan persamaan diferensial yang dinotasikan dalam persamaan operator :

$$
\mathrm{Ly}+\mathrm{Ry}+\mathrm{Ny}=\mathrm{G}
$$

Dengan $\mathrm{N}$ adalah operator nonlinear dan $\mathrm{L}$ adalah operator diferensial linier orde lebih tinggi $\mathrm{R}$ yang diasumsikan dapat dibalik (invertible), $\mathrm{R}$ adalah operator diferensial linear dari orde yang kurang dari L dan G suku nonhomogen.

Persamaan (1) dapat ditulis menjadi

$$
\mathrm{Ly}=\mathrm{G}-\mathrm{Ry}-\mathrm{Ny}
$$

Selanjutnya jika persamaan (2) menggunakan operator $\mathrm{L}^{-1}$ diperoleh

$$
\mathrm{y}=\mathrm{h}+\mathrm{L}^{-1} \mathrm{G}-\mathrm{L}^{-1} \mathrm{Ry}-\mathrm{L}^{-1} \mathrm{Ny}
$$

Dengan $\mathrm{h}$ adalah solusi persamaan homogeny $\mathrm{Ly}=0$ dengan nilai awal atau nilai batas yang diketahui. Kemudian Adomian mendefinisikan solusi y sebagai jumlahan deret tak hingga yaitu

$$
\mathrm{y}=\sum_{\mathrm{n}=0}^{\infty} \mathrm{y}_{\mathrm{n}}
$$

Masalah lebih lanjut adalah pada dekomposisi suku nonlinier Ny, Adomian mendefinisikan sebagai berikut

$$
\mathrm{N}(\mathrm{y})=\sum_{\mathrm{n}=0}^{\infty} \mathrm{A}_{\mathrm{n}}
$$

Dengan

$$
A_{n}=\frac{1}{n !}\left[\frac{d^{n}}{d \lambda^{n}} N \sum_{k=0}^{\infty} y_{k} \lambda^{k}\right]_{\lambda=0}
$$


Selanjutnya komponen $A_{n}$ disebut polinomial Adomian, didefinisikan sebagai:

$$
\begin{aligned}
& A_{0}=N\left(y_{0}\right) \\
& A_{1}=u_{1} N^{\prime}\left(y_{0}\right) \\
& A_{2}=u_{2} N^{\prime}\left(y_{0}\right)+\frac{u_{1}^{2}}{2} N^{\prime \prime}\left(y_{0}\right) \\
& A_{3}=u_{3} N^{\prime}\left(y_{0}\right)+u_{1} u_{2} N^{\prime \prime}\left(y_{0}\right)+\frac{u_{1}^{3}}{3 !} N^{\prime \prime \prime}(y) \\
& \vdots
\end{aligned}
$$

Selanjutnya menggunakan Persamaan (3) dan (4) diperoleh :

$$
\sum_{\mathrm{n}=0}^{\infty} \mathrm{y}_{\mathrm{n}}=\mathrm{h}+\mathrm{L}^{-1} \mathrm{G}-\mathrm{L}^{-1} \mathrm{Ry}-\mathrm{L}^{-1} \mathrm{Ny}
$$

Dengan mensubstitusi persamaan (4) dan (5) ke persamaan (6) diperoleh :

$$
\sum_{\mathrm{n}=0}^{\infty} \mathrm{y}_{\mathrm{n}}=\mathrm{h}+\mathrm{L}^{-1} \mathrm{G}-\mathrm{L}^{-1} \mathrm{R} \sum_{\mathrm{n}=0}^{\infty} \mathrm{y}_{\mathrm{n}}-\mathrm{L}^{-1} \sum_{\mathrm{n}=0}^{\infty} \mathrm{A}_{\mathrm{n}}
$$

Lebih lanjut, Persamaan (7) dapat diuraikan yaitu

$$
\mathrm{y}_{0}=\mathrm{h}+\mathrm{L}^{-1} \mathrm{G}
$$

Dan

$$
\mathrm{y}_{\mathrm{n}}=-\mathrm{L}^{-1}\left(\mathrm{Ry}_{\mathrm{n}-1}\right)-\mathrm{L}^{-1}\left(\mathrm{~A}_{\mathrm{n}-1}\right), \mathrm{n}=1,2,3, \ldots
$$

Kelebihan dari metode dekomposisi Adomian Laplace yaitu solusi yang diperoleh lebih sederhana dalam bentuk deret tak hingga.

\section{Transformasi Laplace}

Transformasi laplace dapat diterapkan sebagai metode untuk menyelesaikan persamaan diferensial, baik sebagai masalah nilai awal maupun masalah nilai batas. (Wahidah, 2015).

Definisi 2.8 (Wahidah, 2015)

Misalkan $\mathrm{f}(\mathrm{t})$ suatu fungsi dari $t$ yang ditentukan untuk $\mathrm{t}>0$. Maka transformasi Laplace dari $\mathrm{f}(\mathrm{t})$, yang dinyatakan oleh $\mathcal{L}\{\mathrm{f}(\mathrm{t})\}$, didefinisikan sebagai,

$$
\mathcal{L}\{\mathrm{f}(\mathrm{t})\}=\mathrm{F}(\mathrm{s})=\int_{0}^{\infty} \mathrm{f}(\mathrm{t}) \mathrm{e}^{-\mathrm{st}} \mathrm{dt}
$$

Definisi 2.9 (Wahidah,2015)

Jika transformasi laplace suatu fungsi $\mathrm{f}(\mathrm{t})$ adalah $\mathrm{F}(\mathrm{s})$, yaitu $\mathcal{L}\{\mathrm{f}(\mathrm{t})\}=\mathrm{F}(\mathrm{s})$ maka $\mathrm{f}(\mathrm{t})$ dinamakan invers transformasi Laplace dari $\mathrm{F}(\mathrm{s})$ dan dinotasikan dengan $\mathrm{f}(\mathrm{t})=\mathcal{L}^{-1}\{\mathrm{~F}(\mathrm{~s})\}$ dengan $\mathrm{L}^{-1}$ disebut operator invers Transformasi Laplace.

Contoh 2.5

Sebuah fungsi $f(t)$ yang didefinisikan dengan

$$
\mathrm{f}(\mathrm{t})=\mathrm{e}^{\text {at }} \quad ; \mathrm{t} \geq 0 \text { dan a konstanta tak nol }
$$

Tentukanlah transformasi laplacenya!

Penyelesaian :

$$
\mathrm{L}\left\{\mathrm{e}^{\mathrm{at}}\right\}=\int_{0}^{\infty} \mathrm{e}^{\mathrm{at}} \mathrm{e}^{-\mathrm{st}} \mathrm{dt}=\lim _{\mathrm{T} \rightarrow \infty} \int_{0}^{\mathrm{T}} \mathrm{e}^{\mathrm{at}-\mathrm{st}} \mathrm{dt}=-\frac{1}{\mathrm{a}-\mathrm{s}} \quad \text { (Wahidah, 2015). }
$$




\section{PROSEDUR}

Prosedur penelitian yang akan diterapkan dalam menentukan solusi persamaan panas dengan menggunakan metode Dekomposisi Adomian Laplace adalah sebagai berikut :

- Menggunakan Transformasi Laplace pada persamaan panas

- Substitusi nilai awal

- Menyatakan solusi dalam bentuk deret tak hingga

- Menggunakan invers Transformasi Laplace.

\section{HASIL DAN PEMBAHASAN}

Bentuk umum persamaan panas dimensi satu dapat ditulis sebagai :

$$
u_{t}=k u_{x x} \quad \text { atau } \quad \frac{\partial u}{\partial t}=k \frac{\partial^{2} u}{\partial x^{2}}
$$

Dengan menetapkan nilai awal persamaan panas dimensi satu sebagai berikut:

$$
u(x, 0)=f(x)
$$

Dalam menentukan solusi dari persamaan (8) di atas, digunakan langkah-langkah berikut:

1. Menggunakan Transformasi Laplace pada persamaan (8)

Transformasi Laplace dari turunan pertama adalah $\mathcal{L}\left\{\frac{\partial u}{\partial t}\right\}=\int_{0}^{\infty} e^{-s t} \frac{\partial u}{\partial t} d t$

$$
\begin{aligned}
\mathcal{L}\left\{\frac{\partial u}{\partial t}\right\} & =\int_{0}^{\infty} e^{-s t} \frac{\partial u}{\partial t} d t \\
& =\lim _{P \rightarrow \infty} \int_{0}^{P} e^{-s t} \frac{\partial u}{\partial t} d t \\
& =s u(x, s)-u(x, 0)
\end{aligned}
$$

Dari uraian diatas, maka Transformasi Laplace dari turunan pertama sebuah fungsi adalah

$$
\mathcal{L}\left\{\frac{\partial u}{\partial t}\right\}=s u(x, s)-u(x, 0)
$$

Untuk transformasi Laplace pada ruas kanan persamaan (8) diperoleh dengan cara berikut dengan menggunakan aturan Leibnitz untuk menurunkan di bawah tanda integral, maka

$$
\mathcal{L}\left\{\frac{\partial u}{\partial x}\right\}=\int_{0}^{\infty} e^{-s t} \frac{\partial u}{\partial x} d t=\frac{d}{d x} \int_{0}^{\infty} e^{-s t} u d t=\frac{d u(x, s)}{d x}
$$

Sehingga, $\mathcal{L}\left\{\frac{\partial^{2} u}{\partial x^{2}}\right\}=\frac{d^{2} u(x, s)}{d x^{2}}$

Maka diperoleh transformasi Laplace dari persamaan (8)

2. Substitusi nilai awal

$$
\begin{gathered}
\mathcal{L}\left\{\frac{\partial u}{\partial t}\right\}=\mathcal{L}\left\{k \frac{\partial^{2} u}{\partial x^{2}}\right\} \\
s u(x, s)-u(x, 0)=k\left(\frac{d^{2} u(x, s)}{d x^{2}}\right)
\end{gathered}
$$

Selanjutnya substitusi nilai awal pada persamaan (9) kedalam persamaan (10)

$$
\begin{gathered}
s u(x, s)-f(x)=k\left(\frac{d^{2} u(x, s)}{d x^{2}}\right) \\
u(x, s)=\frac{f(x)}{s}+\frac{k}{s}\left(\frac{d^{2} u(x, s)}{d x^{2}}\right)
\end{gathered}
$$

3. Menyatakan solusi dalam bentuk deret tak hingga $u=\sum_{n=0}^{\infty} u_{n}$ 
Metode Dekomposisi Adomian mendefinisikan solusi dalam bentuk deret tak hingga, yaitu $u=$ $\sum_{n=0}^{\infty} u_{n}$ dengan $u_{n}$ dihitung secara rekursif.

Hasil yang diperoleh pada persamaan (11) dinyatakan dalam solusi bentuk deret tak hingga $u=$ $\sum_{n=0}^{\infty} u_{n}$

$u(x, s)=\sum_{n=0}^{\infty} u_{n}(x, s)=\frac{f(x)}{s}+\frac{k}{s}\left(\frac{d^{2}}{d x^{2}}\left(\sum_{n=0}^{\infty} u_{n}(x, s)\right)\right)$

Berdasarkan persamaaan (12), diperoleh :

$u_{0}(x, s)=\frac{f(x)}{s}$
$u_{1}(x, s)=\frac{k}{s}\left(\frac{d^{2}}{d x^{2}}\left(\frac{f(x)}{s}\right)\right)$

$\vdots$

$u_{n+1}(x, s)=\frac{k}{s^{(n+1)}}\left(\frac{d^{2(n+1)}}{d x^{2(n+1)}} u_{0}(x, s)\right) \quad, n \geq 0$

Sehingga,

$$
\begin{aligned}
\sum_{n=0}^{\infty} u_{n}(x, s)=\frac{f(x)}{s}+ & \frac{k}{s}\left(\frac{d^{2}}{d x^{2}}\left(\frac{f(x)}{s}\right)\right)+\frac{k}{s^{2}}\left(\frac{d^{4}}{d x^{4}}\left(\frac{f(x)}{s}\right)\right)+\frac{k}{s^{3}}\left(\frac{d^{6}}{d x^{6}}\left(\frac{f(x)}{s}\right)\right)+\cdots \\
& +\frac{k}{s^{(n+1)}}\left(\frac{d^{2(n+1)}}{d x^{2(n+1)}} u_{0}(x, s)\right)
\end{aligned}
$$

Yang menghasilkan

$$
\begin{aligned}
u(x, s)=\frac{f(x)}{s} & +\frac{k}{s}\left(\frac{d^{2}}{d x^{2}}\left(\frac{f(x)}{s}\right)\right)+\frac{k}{s^{2}}\left(\frac{d^{4}}{d x^{4}}\left(\frac{f(x)}{s}\right)\right)+\frac{k}{s^{3}}\left(\frac{d^{6}}{d x^{6}}\left(\frac{f(x)}{s}\right)\right)+\cdots \\
& +\frac{k}{s^{(n+1)}}\left(\frac{d^{2(n+1)}}{d x^{2(n+1)}} u_{0}(x, s)\right)
\end{aligned}
$$

4. Menggunakan invers Transformasi Laplace

Berdasarkan langkah 3 telah diperoleh, $u(x, s)$

Selanjutnya untuk memperoleh $u(x, t)$ digunakan invers transformasi Laplace

$$
\begin{gathered}
u_{0}(x, t)=\mathcal{L}^{-1}\left\{\frac{f(x)}{s}\right\}=f(x) \\
u_{1}(x, t)=k \mathcal{L}^{-1}\left\{\frac{1}{s^{1}}\left(\frac{d^{2}}{d x^{2}}\left(\frac{f(x)}{s}\right)\right)\right\}=k \frac{t}{1 !} \frac{\partial^{2}}{\partial x^{2}} u_{0} \\
\vdots \\
u_{n+1}(x, t)=k \mathcal{L}^{-1}\left\{\frac{1}{s^{(n+1)}}\left(\frac{d^{2(n+1)}}{d x^{2(n+1)}}\left(\frac{f(x)}{s}\right)\right)\right\}=k \frac{t^{n+1}}{(n+1) !} \frac{\partial^{2(n+1)}}{\partial x^{2(n+1)}} u_{0} \quad, n \geq 0
\end{gathered}
$$

Jadi ,

$$
u(x, t)=f(x)+k \frac{t}{1 !} \frac{\partial^{2}}{\partial x^{2}} u_{0}+k \frac{t^{2}}{2 !} \frac{\partial^{4}}{\partial x^{4}} u_{0}+k \frac{t^{3}}{3 !} \frac{\partial^{6}}{\partial x^{6}} u_{0}+\cdots+k \frac{t^{n+1}}{(n+1) !} \frac{\partial^{2(n+1)}}{\partial x^{2(n+1)}} u_{0}
$$




\section{KESIMPULAN}

Solusi dari persamaan panas dimensi satu adalah :

$$
u(x, t)=f(x)+k \frac{t}{1 !} \frac{\partial^{2}}{\partial x^{2}} u_{0}+k \frac{t^{2}}{2 !} \frac{\partial^{4}}{\partial x^{4}} u_{0}+k \frac{t^{3}}{3 !} \frac{\partial^{6}}{\partial x^{6}} u_{0}+\cdots+k \frac{t^{n+1}}{(n+1) !} \frac{\partial^{2(n+1)}}{\partial x^{2(n+1)}} u_{0}
$$

Dengan nilai awal $u(x, 0)=f(x)$.

Dengan demikian, Metode Dekomposisi Adomian Laplace dapat digunakan dalam menyelesaikan persamaan panas dimensi satu.

\section{REFERENSI}

Azis, Moh.Ivan. 2011. Metode Elemen Batas (MEB) untuk model konduksi panas. Jurnal Fisika FUSI Jurusan Fisika FMIPA Unhas. 6(8).35-43.

Edwards,C.Henry.,Penney,david E. 2001. Differential Equations \& Linear Algebra. New Jersey: Prentice-Hall.

Kartono, 1994. Penuntun Belajar Persamaan Differensial. Yogyakarta: Andi Offset.

Kusumah, Yaya S. 1989. Persamaan Differensial. Departemen Pendidikan dan Kebudayaan, Direktorat Jenderal Pendidikan Tinggi. Jakarta.

Meyriska, Aulia Harini. 2005. Transformasi Laplace dari Masalah Nilai Batas pada Persamaan Diferensial Parsial. (Skripsi, tidak dipublikasikan). Universitas Negeri Semarang.

Moentiarsanto, Djoko., Cahyono,Bambang Tri. 1982. Persamaan Diferensial. Yogyakarta: Ananda.

Santosa, Widiarti \& RJ. Pamuntjak. 1994. Persamaan Differensial Biasa. Proyek Pendidikan Tinggi Tenaga Akademika. Departemen Pendidikan dan Kebudayaan, Direktorat Jenderal Pendidikan Tinggi. Proyek Lembaga Pendidikan Tenaga Kependidikan. Jakarta

Satriani, Lili. 2015. Solusi Persamaan Gelombang dengan Metode Dekomposisi Adomian Laplace. (Skripsi, tidak dipublikasikan). Fakultas Matematika dan Ilmu Pengetahuan Alam Universitas Negeri Makassar.

Side, Syafruddin. 2016. Persamaan Diferensial Parsial. Makassar: Universitas Negeri Makassar.

Simmons,George F.,Krantz,Steven G. 2007. Differential Equations : Theory, Technique, and Practice. New York: McGraw-Hill.

Strauss, Walter A. 1992. Partial Differential Equations an Introduction. Canada: John Wiley \& Sons,Inc.

Wahidah,Wahyuni, \& Ratnasari. 2015. Fungsi Green yang dikonstruksi pada Persamaan Diferensial Linear Tak Homogen Orde-n. Jurnal MSA . 3(1).

Wartono, Muhaijir. 2013. Penyelesaiaan Persamaan Riccati dengan menggunakan Metode Dekomposisi Adomian Laplace. Jurnal Sains, Teknologi, dan Industri. 10(2).

Yuni, Yulida. 2012. Metode Dekomposisi Adomian Laplace untuk Solusi Persamaan Diferensial Nonlinear Koefisien Fungsi. Jurnal Matematika Murni dan Terapan. 6(1).17-26. 